\title{
ESTUDO DE CASO DA UTILIZAÇÃO DO RCD (RESÍDUOS DE CONSTRUÇÃO E DEMOLIÇÃO) NA REPARAÇÃO DE RUAS E AVENIDAS DE PIRACICABA SP
}

\section{CASE STUDY: \\ USE OF CONSTRUCTION AND DEMOLITION RESIDUES IN ROAD REPAIR WORK IN PIRACICABA-SP}

\section{Vedroni, W. José ${ }^{(1)}$, Carvalho, David de $\mathrm{d}^{(2)}$}

Faculdade de Engenharia Agrícola - FEAGRI - UNICAMP - Barão Geraldo, Campinas - SP. ${ }^{1}$ jose.vedroni@terra.com.br

2david@agr.unicamp.br

\section{RESUMO}

Este trabalho refere-se a um estudo de caso de aplicação da parcela mineral do RCD (Resíduos Sólidos de Construção e Demolição), popularmente conhecidos como entulhos, oriundos das novas construções, reformas e demolições na cidade de Piracicaba-SP. Estes resíduos são facilmente encontrados no meio urbano, nos logradouros públicos, nas encostas, próximos a cursos de água e em áreas verdes ou institucionais, depositados de forma irregular, tornando o visual urbano desagradável, além de servir de vetor para a proliferação de doenças e contaminações. Este estudo concentrou-se na parcela mineral do RCD no que se refere às suas características físicas, mecânicas e químicas, com análises para detecção de possíveis contaminantes. Em Piracicaba, foi aplicada uma metodologia de fechamento de valas com essa parcela mineral do RCD, adicionando-se uma porcentagem de cimento, na reparação de ruas e avenidas executada pelo SEMAE (Serviço Municipal de Água e Esgoto). Desta maneira, sua utilização torna-se uma fonte de vazão para aplicação, como matéria prima, contribuindo com a preservação do meio ambiente, diminuindo a retirada de recursos naturais e o volume de aterro de inertes e, assim, cumprindo com as exigências da legislação atual vigente que trata da gestão sustentável de resíduos de construção.

Palavras-chave: Entulhos. Resíduos sólidos. RCD. Reciclagem. Valas. 


\begin{abstract}
This paper refers to a case study of application of the mineral portion of Construction and Demolition Residues (CDR) originating from new construction, renovations, and demolition in the city of Piracicaba-SP. These residues are easily found on urban public areas, on hillsides, close to streams and in green or institutional areas, deposited in an irregular way, spoiling the urban scenery and also serving as a vector for the proliferation of diseases and contamination. The study concentrated on the mineral portion of CDR, refering to its physical, mechanical and chemical characteristics, with analyses for the detection of possible pollutants. A methodology is proposed: by adding a percentage of cement, it can be used to repave roads following maintenance work on the water supply and sewer system performed by SEMAE (Municipal Service of Water and Sewer). In this manner, this 'product' becomes a source of raw material for application, contributing to the preservation of the environment, reducing the removal of natural resources and the volume of inert fill, thus satisfying the demands of current legislation in force, which deals with the sustainable management of construction residues.
\end{abstract}

Keywords: Solid Residues. Construction and Demolition. Residues. Recycling. Ditches.

\title{
1. INTRODUÇÃO
}

A geração de resíduos dos mais diferentes tipos é uma característica da atual população. Uma das conseqüências dessa realidade é que o planeta vem constantemente se modificando, passando por um processo de reorganização, muitas vezes desastrosa para o eco-sistema. Tendo em vista os novos paradigmas para a preservação do meio ambiente, como o desenvolvimento sustentável, o aumento da sustentabilidade e a eco-eficiência, busca-se despertar a consciência de que a natureza não é fonte ilimitada de recursos à disposição do homem.

Porém, atualmente, o descarte dos resíduos da construção civil ocorre sem a preocupação com o meio ambiente. Tal prática pode ser notada em aterros sanitários, logradouros públicos, corpos d'água, áreas verdes ou em outros espaços públicos, sem levar em conta os possíveis impactos que possam ser gerados na natureza.

Uma das soluções para esse problema pode ser a reutilização desse material, como a que vem proposta neste estudo de caso, que tem como objetivo analisar o RCD (Resíduos de Construção e Demolição) e a viabilidade da sua utilização na repavimentação de ruas e avenidas, após reparos nas tubulações que fornecem água e retiram os esgotos de cidades. 


\section{HISTÓRICO}

Sabe-se que os primeiros registros de reutilização dos resíduos da construção civil na produção de novas obras vieram do Império Romano, mas, a primeira aplicação significativa de entulho reciclado foi registrada somente após o final da Segunda Guerra Mundial, na reconstrução das cidades européias.

Na Europa, (COELHO e CHAVES, 1998; apud LIXO MUNICIPAL, 2000), os incentivos fiscais à reciclagem, mesmo indiretos, favorecem o surgimento da reciclagem feita pelas próprias mineradoras, como, por exemplo, a Superfos, que tem uma usina com três britadores, custo de cerca de US\$ 1 milhão e é operada por apenas três pessoas.

Segundo (MEHTA e MONTEIRO, 1994; apud LIXO MUNICIPAL, 2000), como exemplo de aplicação, tem-se uma das rodovias mais antigas e movimentadas do estado de Michigan, que em 1983 se tornou à primeira rodovia de grande porte nos Estados Unidos a reciclar concreto. Em uma extensão de 5,7 milhas de seção toda deteriorada, o pavimento de concreto foi usado novamente como agregado na construção do novo pavimento.

Vários países desenvolvidos, por sentirem problemas na escassez dos recursos naturais e/ou problemas no gerenciamento da questão ambiental, têm direcionado esforços na reciclagem do resíduo, entre eles, podem ser citados por (LEVY, 1997):

- Estados Unidos, onde tem havido esforços para o uso de agregados reciclados por meio de britagem de concretos de demolição para a área de construção de pavimentos rodoviários;

- Holanda, onde há proposição de norma para produção de concreto simples, armado e protendido, que garante o uso de agregados obtidos pela reciclagem de concreto, misturados a agregados originais, com quantidade acima de vinte por cento do total de agregados utilizados;

- Japão, onde, a exemplo do que acontece nos Estados Unidos, detecta-se um encaminhamento na direção da normalização de agregados obtidos por reciclagem de estruturas e pavimentos de concreto demolidos;

\section{CLASSIFICAÇÃO}

\subsection{ABNT}

Segundo a Associação Brasileira de Normas Técnicas - NBR 10004 (ABNT 2004a)

Os resíduos são classificados em: CLASSE I (perigosos) e Classe II (não perigosos).

Dentro da Classe II, tem-se a Classe II A (não inertes) que são aqueles que têm propriedades tais como combustibilidade, biodegradabilidade ou solubilidade em água, e a Classe II B (inertes) que são quaisquer resíduos que, quando amostrados de uma forma representativa, segundo a NBR 10007 (ABNT 2004d) e submetidos a um 
contato dinâmico e estático com água destilada ou desionizada, à temperatura ambiente, conforme norma técnica NBR 10006 (ABNT 2004c), não tem em seus constituintes, concentrações superiores aos padrões de potabilidade de água, excetuando-se os aspectos cor, turbidez, dureza e sabor, conforme anexo G.

\subsection{CONAMA}

Segundo a Resolução do Conselho Nacional do Meio Ambiente - CONAMA $\mathrm{n}^{\circ}$ 307, (BRASIL, 2002) o RCD foi classificado como:

- Classe A - alvenaria, concreto, argamassas e solos. Destinação: reutilização ou reciclagem com uso na forma de agregados, além da disposição final em aterros licenciados;

- Classe B - madeira, metal, plástico e papel. Destinação: reutilização, reciclagem ou armazenamento temporário;

- Classe C - produtos sem tecnologia disponível para recuperação (gesso). Destinação: conforme norma técnica específica;

- Classe D - resíduos perigosos (tintas, óleos, solventes, amianto etc).

\section{LOCAL DO ESTUDO}

Em Piracicaba, onde está sendo empregada essa metodologia de reciclagem dos resíduos, é uma cidade em desenvolvimento, com estimativas de grande potencial para o crescimento, tem uma população estimada em trezentos e quarenta mil habitantes, segundo fonte do Instituto Brasileiro de Geografia e Estatística (IBGE 2002). O município abriga diversas empresas importantes, dentre as mais conhecidas a Caterpillar e a Belgo Mineira, na área agrícola há a predominância da monocultura da cana-de-açúcar.

A geração de RSU (Resíduos Sólidos Urbanos) é de duzentos e seis toneladas dia, conforme fonte da Secretaria do Meio Ambiente de São Paulo, por meio de seu inventário Estadual de Resíduos Sólidos Domiciliares de dois mil e quatro.

No município a geração do RCD é de aproximadamente cinquenta por cento do RSU, segundo fonte da Prefeitura local quando da realização de seu diagnóstico no ano de dois mil e um, para aplicação do Plano Integrado dos Resíduos Sólidos.

Segundo dados fornecidos pela Empresa Municipal de Habitação de Piracicaba - EMDHAP, responsável pela usina de reciclagem, em dois mil e quatro foram beneficiados cento e cinco toneladas de resíduos por dia.

Os resíduos, quando não utilizados, são destinados ao aterro sanitário, onerando o custo para o município e acarretando impactos ambientais.

A freqüência de manutenção realizada pelo Serviço Municipal de Água e Esgoto - SEMAE autarquia responsável pelo fornecimento de água e na retirada e tratamentos dos esgotos do município de Piracicaba-SP, em suas redes que ficam sob 
a pavimentação, é em torno de três mil e cem intervenções por ano segundo o SEMAE.

A metodologia proposta substitui o sistema tradicional de uso de recursos naturais "agregados primários e solo" para fechamento das valas abertas e reparação do pavimento, por um sistema que utiliza materiais reciclados de forma sustentável.

\section{OBJETIVOS}

O presente trabalho tem como objetivo investigar a parcela mineral do RCD como matéria prima e apresentar uma metodologia de sua aplicação, com adição de uma porcentagem de cimento, para obras de reparação realizada pelo SEMAE em Piracicaba.

\subsection{Objetivos Específicos}

Para o RCD obtido na cidade de Piracicaba determinar:

$\checkmark$ características físicas;

$\checkmark$ características de resistência mecânica quando compactado;

$\checkmark$ a presença de possíveis contaminantes;

$\checkmark$ metodologia de aplicação.

\section{MATERIAIS E MÉTODOS}

O material utilizado é a parcela mineral do RCD. Após passar pela triagem e separá-lo dos demais resíduos, a reciclagem é realizada em uma usina de britagem, onde é possível o beneficiamento destes resíduos, conforme Figura 1.

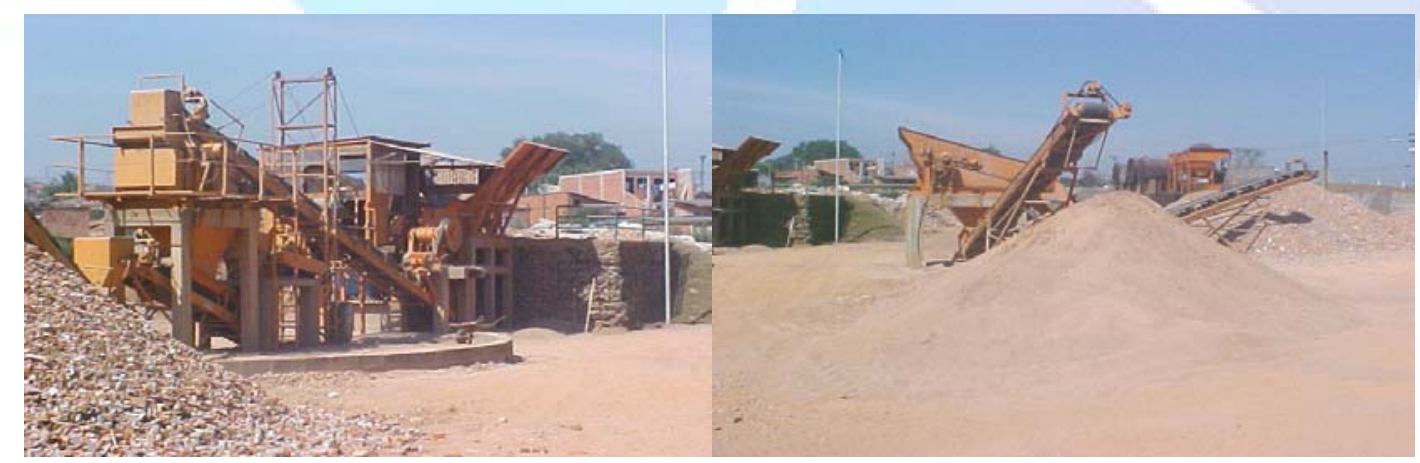

Figura 1. Usina de reciclagem de resíduos.

O equipamento capaz de fazer este processo é chamado britador, que neste caso é o do tipo mandíbula. Os resíduos passam por ele e são britados e transportados por uma correia até as peneiras, que os separam em: areia, pedrisco, brita 1,2 e a bica 
corrida sem a passagem pela peneira (material britado não classificado e extraído diretamente após britagem secundária).

Os materiais utilizados neste estudo de caso foram: a bica corrida, com diâmetro de até dezenove milímetros e areia, com diâmetro abaixo de 4,8 $\mathrm{mm}$. Estes materiais foram utilizados para o fechamento das valas e na repavimentação em Piracicaba, conforme metodologia que será detalhada adiante.

Para sua aplicação, foram estudadas suas propriedades químicas (para verificação quanto a possíveis contaminantes), físicas e mecânicas, ensaiadas a partir da coleta dos materiais na usina de reciclagem durante três dias consecutivos de produção.

\subsection{Ensaios}

\subsubsection{Propriedades Químicas}

As análises de Lixiviação foram realizadas conforme recomenda a norma técnica ABNT NBR 10005 (ABNT 2005b), metodologia: "Stand methods for the Examination of Water and Wastewater $-20^{\text {th }}$ ed. and "USEPA SW- 846 - Test Methods for Evaluation Solid Waste-Physical/Chemical Methods".

As análises de Solubilização foram realizadas conforme recomenda a NBR 10006 (ABNT 2004c), metodologia: "Stand methods for the Examination of Water and Wastewater $-20^{\text {th }}$ ed. and "USEPA SW- 846 - Test Methods for Evaluation Solid Waste-Physical/Chemical Methods".

\subsubsection{Limites de Consistência}

Os limites de consistência permitem avaliar os de liquidez, plasticidade e contração dos solos. Dentre os ensaios de rotina, para caracterização desses limites, está a determinação do limite de liquidez e limite de plasticidade conforme DEPARTAMENTO NACIONAL DE ESTRADAS E RODAGEM (DNER, 1994b e c) respectivamente.

O limite de liquidez permite identificar a umidade de transição entre o estado líquido e plástico de um determinado material. Já o limite de plasticidade indica a umidade de transição entre o estado plástico e o semi-sólido. $\mathrm{O}$ índice de plasticidade é obtido pela diferença sendo:

Índice de plasticidade, IP $=\mathrm{LL}-\mathrm{LP}$

Equação (1)

O índice de plasticidade (IP) corresponde à faixa de valores de umidade do solo, na qual ele se comporta de maneira plástica, é a diferença numérica entre o valor do limite de liquidez e o limite de plasticidade. 


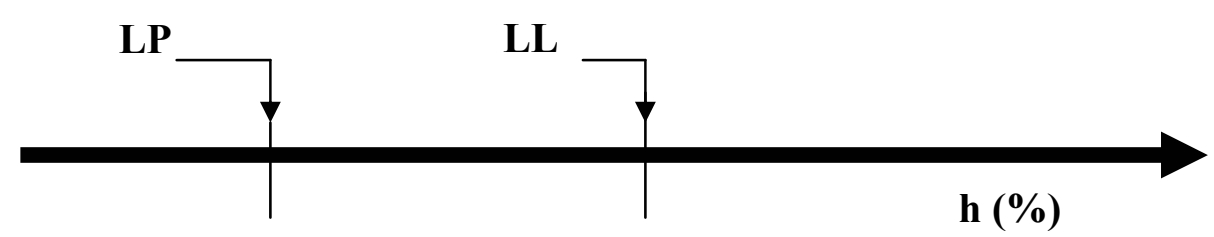

Ambos são teores de umidade (h), que indicam:

$\mathrm{LL}=$ Limite de Liquidez (LL é a passagem do estado plástico para o líquido);

LP = Limite de Plasticidade (LP é a passagem do estado semi-sólido para o plástico).

\subsubsection{Granulometria}

A curva granulométrica (ABNT, 1984a) permite distinguir tipos diferentes de diâmetro dos grãos, identificar um solo como sendo bem ou mal graduado e auxiliar na identificação das características de uniformidade e graduação dos solos, definindo os seguintes índices:

Diâmetro efetivo (D10 ou De): diâmetro correspondente a 10\% em peso total de todas as partículas menores que ele, sendo D30 e D60 (diâmetros correspondentes a $30 \%$ e $60 \%$ em peso total das partículas menores que eles).

Grau de uniformidade (U): indica a falta de uniformidade, sendo tanto menor quanto mais uniforme for o solo, sendo:

$$
\mathrm{U}=\mathrm{D} 60 / \mathrm{D} 10
$$

Equação (2)

Quanto menor o grau de uniformidade, maior é a inclinação da curva granulométrica e o solo é melhor graduado, segundo a seguinte classificação:

$$
\begin{gathered}
\mathrm{U}<5 \rightarrow \text { muito uniforme } \\
5<\mathrm{U}<15 \rightarrow \text { uniformidade média } \\
\mathrm{U}>15 \rightarrow \text { desuniforme }
\end{gathered}
$$

Alguns autores consideram solos uniformes os que têm grau de uniformidade menor que três, e desuniformes os que têm $U>3$.

\section{Coeficiente de curvatura (CC):}

$$
\mathrm{CC}=(\mathrm{D} 30)^{2} /(\mathrm{D} 10 * \mathrm{D} 60)
$$

Solos bem graduados têm $1<\mathrm{CC}<3$. 


\subsection{4. Índice Suporte Califórnia}

É determinado através do ensaio CBR, (California Bearing Ratio), também chamado de ensaio California ou ensaio Californiano (introduzido por Porter 1929), ou Índice Suporte California (ISC). O ensaio consiste na determinação da relação entre a pressão necessária para produzir uma penetração de um pistão num corpo-deprova, e a pressão necessária para produzir a mesma penetração numa brita padronizada.

O ensaio determina a resistência mecânica na compactação desejada, podendo ser definido como a relação percentual entre a pressão necessária para fazer penetrar, de maneira padronizada, um pistão cilíndrico $19,35 \mathrm{~cm}^{2}$, em uma amostra de solo convenientemente preparada a uma velocidade de $1,25 \mathrm{~mm} / \mathrm{min}$.

Primeiramente, mede-se a pressão aplicada (manômetro ou anel dinamométrico), exigindo-se a pressão de $70 \mathrm{kgf} / \mathrm{cm}^{2}$ para a penetração de $2,54 \mathrm{~mm}$ ou $105 \mathrm{kgf} / \mathrm{cm}^{2}$ para a penetração de $5,08 \mathrm{~mm}$, e a respectiva curva deformação do CBR. Caso haja necessidade, faz-se a correção da curva em relação ao ponto inicial para a carga de 70 e $105 \mathrm{kgf} / \mathrm{cm}^{2}$, respectivamente, adotando-se o maior valor. $\mathrm{O}$ ensaio também mede a expansão do solo após 96 horas da amostra embebida em água, o CBR é dado por:

$$
\begin{array}{rlr}
C B R(\%) & =\frac{\text { pressão } 2,54 \mathrm{~mm}}{70} \times 100 & \text { Equação (4) } \\
\text { OU } & \\
C B R(\%)=\frac{\text { pressão } 5,08 \mathrm{~mm}}{105} \times 100 & \text { Equação (5) } \\
\mathrm{P}_{1} \text { e } \mathrm{P}_{2} \text { : Pressões lidas para } 2,54 \text { e } 5,08 \mathrm{~mm} ; &
\end{array}
$$$$
\mathrm{P}_{1^{\prime}} \text { e } \mathrm{P}_{2}: \text { : Pressões corrigidas para 2,54 e 5,08mm. }
$$

\subsubsection{Compressão Axial}

O ensaio de resistência à compressão simples DNER-ME 201:1994 mede a resistência de um cilindro de solo submetido à compressão axial $\left(\sigma_{1}\right)$ desprovido de suporte lateral $\left(\sigma_{3}=0\right)$. $\mathrm{O}$ resultado poderá ser obtido após apresentar resistência da ruptura dos corpos-de-prova, a 7 e aos 28 dias da moldagem e cura em câmara úmida.

\section{RESULTADOS}

\section{1. Índice Suporte Califórnia (CBR)}

Os ensaios foram realizados conforme a Norma DNER-ME 049 (DNER, 1994a), variando-se a energia de compactação, sendo os valores obtidos a partir de amostras virgens e em cinco corpos-de-prova para cada energia de compactação. A Tabela 1 apresenta a média dos resultados destes ensaios, dentre os resultados dos ensaios obtidos, o da EC (energia de compactação) intermediária. 
Tabela 1 - Resumo ensaios de CBR após imersão em água por 4 dias.

\begin{tabular}{l|c|c}
\hline \multicolumn{1}{c|}{ EC - ENERGIA DE COMPACTAÇÃO } & CBR \% & EXPANSÃO \% \\
\hline Ensaios com 19 golpes & 37 & 0,5 \\
Ensaios com 26 golpes & 54 & 0,3 \\
Ensaios com 36 golpes & 78 & 0,2 \\
Ensaios com 46 golpes & 92 & 0,0 \\
Ensaios com 55 golpes & 124 & 0,0 \\
\hline
\end{tabular}

\subsection{Compressão Simples}

Procedeu-se à ruptura de amostras no ensaio de compressão simples, em corpos-de-prova com adição de três e seis por cento de cimento CP II Portland ao material reciclado e compactação na EC intermediária e na umidade ótima, encontrando-se os resultados na Tabela 2.

Tabela 2 - Resumo dos ensaios de compressão simples.

\begin{tabular}{c|c|c}
\hline ENSAIO & $\begin{array}{c}\text { CIMENTO EM MASSA 3\% } \\
\text { RESULTADOS em MPa }\end{array}$ & $\begin{array}{c}\text { CIMENTO EM MASSA 6\% } \\
\text { RESULTADOS em MPa }\end{array}$ \\
\hline 1 & 1,7 & 2,6 \\
2 & 1,8 & 2,7 \\
3 & 1,6 & 2,8 \\
MÉDIA & 1,7 & 2,7 \\
\hline
\end{tabular}

\subsection{Granulometria}

Na Figura 2, apresenta-se a curva granulométrica encontrada nos ensaios da bica corrida, sendo as porcentagens do material que passa nas peneiras obtidas conforme a Norma NBR 7181 (ABNT, 1984a).

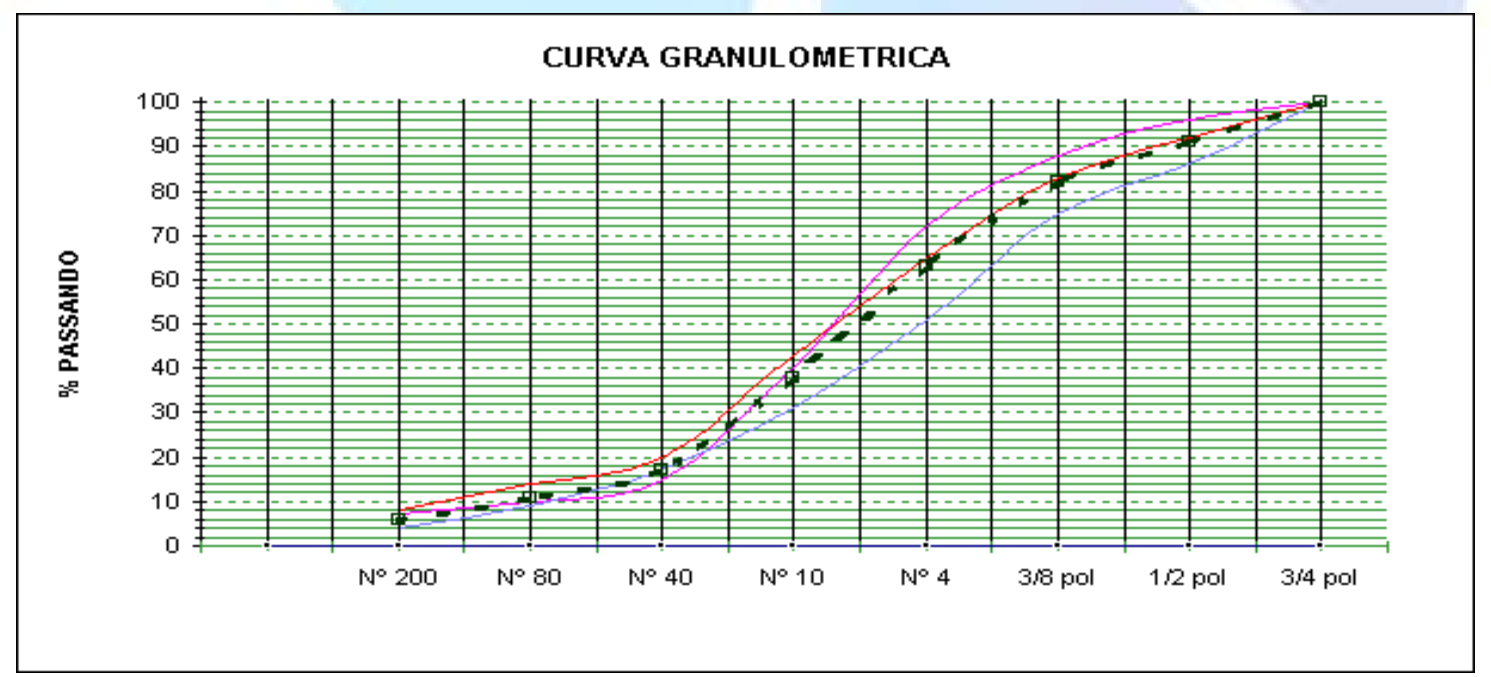

Figura 2. Curva granulométrica da Bica Corrida. 
Valores encontrados:

- Dimensão máxima característica $=19 \mathrm{~mm}$;

- Grau de Uniformidade $(\mathrm{U})=6$;

- Coeficiente de Curvatura $(\mathrm{Cc})=1,8$;

- Material $<0,42 \mathrm{~mm}=18,7 \%$.

\subsection{Limite de Liquidez e Plasticidade}

Lembrando-se que o limite de liquidez indica a quantidade de água que pode ser absorvida pela fração do solo, que passa pela peneira $n .^{\circ} 40(0,42 \mathrm{~mm}$ de abertura da malha). Quanto maior o limite de liquidez tanto mais compressível será o solo, e que este limite é em função da quantidade e do tipo de argila. Quando um material não tem plasticidade areia, por exemplo, escreve-se NP (não plástico).

O ensaio de limite de liquidez foi executado conforme normas do DNER já descrita acima e o valor encontrado foi de vinte e um por cento. Quanto ao ensaio de limite de plasticidade não foi possível a sua execução e atribuindo sua classificação como NP (não plástico).

\subsection{Lixiviação e Solubilização}

Os ensaios foram executados no Laboratório Thomson de Espectrometria de Massas do Instituto de Química da UNICAMP. O RCD apresentou aspecto sólido, cor marrom, umidade igual a cinco vírgula zero quatro por cento. Segundo o "TEST PAINT FILTER", o resíduo não apresentou líquidos livres, quando $100 \mathrm{~g}$ do material foi suspenso durante cinco minutos no funil de malha 60 mesh. No extrato solubilizado encontrou-se $34,5 \mathrm{mg} / \mathrm{L}$ de Nitrato conforme Tabela 3.

Sua classificação, conforme NBR 10004 (ABNT 2004a) é de material CLASSE II A - NÃO PERIGOSO, NÃO INERTE. 
Tabela 3 - Análises Físico-Químicas.

\begin{tabular}{|c|c|c|c|c|}
\hline \multirow[b]{2}{*}{ Parâmetros } & \multicolumn{2}{|c|}{ Solubilizado } & \multicolumn{2}{|c|}{ Lixiviado } \\
\hline & $\begin{array}{c}\text { Resultado } \\
(\mathrm{mg} / \mathrm{L})\end{array}$ & $\begin{array}{c}\text { VMP } \\
(\mathrm{mg} / \mathrm{L})\end{array}$ & $\begin{array}{c}\text { Resultado } \\
(\mathrm{mg} / \mathrm{kg})\end{array}$ & $\begin{array}{c}\text { VPM } \\
(\mathrm{mg} / \mathrm{kg})\end{array}$ \\
\hline Óleo e graxas & $\mathrm{x}$ & $\#$ & $\mathrm{x}$ & $5 \%$ \\
\hline Alumínio & $<0,1$ & 0,2 & $\mathrm{x}$ & $\#$ \\
\hline Arsênio & $<0,05$ & 0,05 & $<0,5$ & 5 \\
\hline Bário & $<0,1$ & 1 & $<0,1$ & 100 \\
\hline Cádmio & $<0,005$ & 0,005 & $<0,02$ & 0,5 \\
\hline Chumbo & $<0,05$ & 0,05 & $<0,05$ & 5 \\
\hline Cobre & $<0,02$ & 2,0 & $\mathrm{x}$ & $\#$ \\
\hline Crômo total & $<0,05$ & 0,05 & $<0,05$ & 5 \\
\hline Manganês & $<0,002$ & 0,1 & $\mathrm{x}$ & \# \\
\hline Mercúrio & $<0,01$ & 0,001 & $<0,001$ & 0,1 \\
\hline Prata & $<0,001$ & 0,05 & $<0,01$ & 5 \\
\hline Selênio & $<0,01$ & 0,01 & $<0,6$ & 1 \\
\hline Sódio & 12,5 & 200 & $\mathrm{x}$ & $\#$ \\
\hline Zinco & $<0,02$ & 5 & $\mathrm{X}$ & $\#$ \\
\hline Ferro & 0,1 & 0,3 & $\mathrm{x}$ & \# \\
\hline Cianetos & 0,015 & 0,1 & $\mathrm{x}$ & \# \\
\hline Cloretos & 10 & 250 & $\mathrm{x}$ & \# \\
\hline Dureza & 232 & 500 & $\mathrm{x}$ & $\#$ \\
\hline Fenóis & $<0,001$ & 0,001 & $\mathrm{x}$ & $\#$ \\
\hline Fluoretos & 1 & & 2 & 150 \\
\hline Nitratos & 34,5 & 10 & $\mathbf{x}$ & $\#$ \\
\hline Sulfatos & 216 & 400 & $\mathrm{x}$ & $\#$ \\
\hline Surfactantes & 0,27 & 0,2 & $\mathrm{x}$ & \# \\
\hline
\end{tabular}




\section{APLICAÇÃO DO MÉTODO}

\subsection{Fechamento da Vala}

Para a realização dos serviços de "tapa-vala", (FORTES et al., 2005) faz a seguinte analogia: "O (a) dentista no tratamento de uma cárie retira todo o material afetado, limpa bem a área de maneira a garantir a aderência do material a ser colocado. No caso do pavimento, é necessário que o recorte possua uma forma geométrica definida (seja requadrado), devendo ser retirado todo material afetado e limpa a área."

- Na primeira etapa do método coloca-se agregados finos (areia), oriundos da reciclagem do $\mathrm{RCD}$, em uma camada de aproximadamente trinta centímetros sobre a geratriz superior da tubulação, tomando-se cuidado para não danificar-la.

A função desta camada é proteger os tubos de possíveis agregados que possam danificá-los e absorver o excesso de umidade causado pelos vazamentos durante o processo de reparo, executando-se então a compactação, com cuidado para não danificar a tubulação reparada.

- A segunda etapa é o fechamento, devendo ser feito em camadas de vinte em vinte centímetros aproximadamente, com a bica corrida do RCD, corrigindo-se a umidade com a adição de água, se necessário e faz-se a compactação com o compactador mecânico manual (sapo) até atingir-se o grau desejado de noventa e cinco por cento da energia normal de compactação, até vinte ou dezoito centímetros do topo da vala.

- A terceira etapa é a execução da camada de base, que deverá ser realizada com mais cuidado, pois é esta camada que irá absorver a maioria dos esforços transmitidos pelo tráfego local. Nesta camada é adicionado seis por cento de cimento Portland em massa à bica corrida originária do $\mathrm{RCD}$, e adicionando-se água para corrigir a umidade se necessário, a função do cimento é para garantir mais uniformidade de resistência ao material. Procede-se à compactação até noventa e cinco por cento da energia intermediária de compactação, conforme o processo descrito na segunda etapa, deixando-se três centímetros de espaço para ruas de baixo tráfego comercial (carga no eixo simples e rodas duplas de $80 \mathrm{kN}$ ) e cinco centímetros para ruas e avenidas com alto tráfego comercial conforme a mesma carga por eixo, a serem preenchidos, formando a camada de rolamento.

- A quarta etapa é a camada de rolamento, de três ou a de cinco centímetros, tendo a função de dar condições e conforto ao tráfego local, sendo realizada logo após o processo de cura da base, três dias após a realização dos serviços. São conferidos os perfis transversais, longitudinais e, caso seja necessário, faz-se à correção da base com a bica corrida, compactando com rolo.

Após a correção aplica-se o CBUQ (Concreto Betuminoso Usinado a Quente), manualmente. Recomenda-se a faixa granulométrica $\mathrm{C}$ do Departamento de Estradas e Rodagem de São Paulo - DER-SP. Antes da aplicação do CBUQ, é necessária à aplicação de uma pintura de ligação com emulsão betuminosa do tipo cura rápida $R R$ 
1C ou RR 2C recordada com água em meio a meio, após a compactação, libera-se a via para o trânsito.

A Figura 3 ilustra toda a metodologia proposta neste artigo.

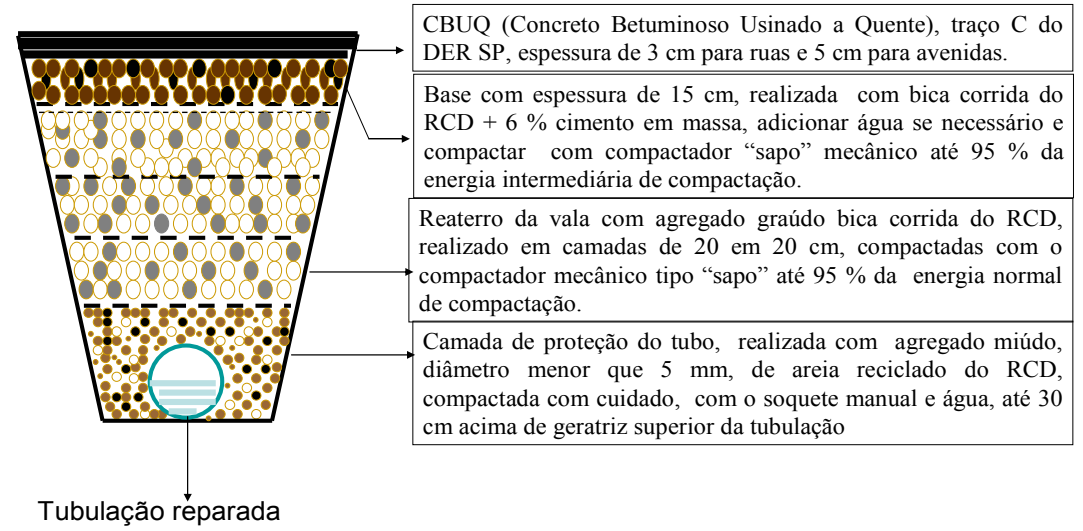

Figura 3. Corte típico do método proposto para fechamento de vala.

\section{ANÁLISE DOS RESULTADOS}

A energia de compactação que melhor atendeu o método foi à intermediária, apresentando um bom valor de suporte e nenhuma expansão. A partir dos ensaios realizados, foi possível fazer uma análise à luz das exigências para utilização do RCD como material alternativo para fechamentos de valas, nas aplicações como bases e sub-bases de pavimentos.

Tendo em vista as características encontradas no RCD de Piracicaba, conforme resultados dos ensaios apresentados e Normas para o Dimensionamento de Pavimentos, verifica-se que é possível a utilização do material. Esta afirmação baseia-se nas seguintes condições especificadas pelas Normas:

- DNIT (DNER) - Condições de materiais para dimensionamento:

Subleitos: CBR $\geq 2 \%$; reforço de subleitos: material granular CBR $\geq 20 \%$ e expansão menor ou igual a $1 \%$ com sobrecarga de $4,5 \mathrm{~kg}$ e bases: CBR $\geq 80 \%$, expansão $\leq 0,5 \%$, equivalente de areia superior a $30 \%$ (para $\mathrm{N} \leq 10^{6}$, o valor de CBR poderá ser $\geq 60 \%)$.

- PMSP - (Prefeitura Municipal de São Paulo), condições de materiais para dimensionamento: subleitos: $\mathrm{CBR} \geq 12 \%$, expansão $\leq 1,0 \%$ compactados na energia 
normal; sub-bases: $\mathrm{CBR} \geq 20 \%$ e expansão $\leq 1 \%$ compactado na energia intermediária; bases mista somente para vias de tráfego com $\mathrm{N} \leq 10^{5}$ repetições do eixo padrão de $80 \mathrm{kN}$ no período, valor de CBR $\geq 60 \%$ e expansão $\leq 0,5 \%$, coeficiente de curvatura entre 1 e 3 e coeficiente de uniformidade $\mathrm{Cu} \geq 10$. A porcentagem que passa na peneira $0,42 \mathrm{~mm}\left(\mathrm{n}^{\circ} 40\right)$ deverá ficar entre 10 e $30 \%$. No caso de adição de cimento e/ou cal hidratada, o material deverá ser submetido ao ensaio de resistência à compressão simples, após 7 dias de cura e apresentar resistência de no mínimo 2,1 $\mathrm{MPa}$, em corpos-de-prova moldados na energia de compactação especificada.

- ABNT NBR 15116 (ABNT, 2004e), define os requisitos dos agregados reciclados para a utilização em pavimentação e preparo de concreto sem função estrutural, cujo coeficiente de uniformidade deverá ser maior que 10 e CBR $\geq 20 \%$.

- ABNT NBR 11804 (ABNT, 1991), especificação para materiais de base e sub-base de pavimentos estabilizados granulometricamente. Ainda, segundo a mesma norma, para execução de camadas estabilizadas granulometricamente, a porcentagem de material que passa pela peneira de $0,074 \mathrm{~mm}$ deve ser inferior a $2 / 3$ da porcentagem que passa pela peneira de $0,42 \mathrm{~mm}$, sendo:

$$
\text { Índice de Forma }=2 / 3 * \% \# 0,42 \mathrm{~mm}
$$

Equação (6)

Resolvendo-se a equação (6), obtém-se um valor de 12,5, que é maior que $6,3 \%$, que é a porcentagem do material que passa na peneira de abertura $0,074 \mathrm{~mm}$, enquadrando-se também nestas normas.

\section{CONCLUSÃO E RECOMENDAÇÃO}

A aplicação do RCD (Resíduos de Construção e Demolição) só foi possível após o município ter implantado o sistema de gestão sustentável dos resíduos de construção, pois o sistema garante a disponibilidade dos resíduos como matéria prima.

Segundo as normas atuais, o RCD de Piracicaba pode ser utilizado para fins específicos. Porém, para garantir-se a qualidade do material dentro das normas, é necessário um controle mais rigoroso na seleção, para que a quantidade de Nitratos não fique acima dos padrões estabelecidos. Orienta-se realizar um número maior de ensaios, a fim de obter-se um banco de dados mais representativo para seu controle.

$\mathrm{O}$ valor de CBR que melhor atende ao estudo é o da energia intermediária. $\mathrm{O}$ Coeficiente de Uniformidade encontrado foi de cinco, que é menor que o valor requerido pela norma, que é de dez. Porém, este fato não trouxe nenhuma dificuldade em se trabalhar com o material.

Pode-se avaliar que o desempenho do pavimento é bom, pois nesse período após sua realização, de três anos em uso, não apresenta problemas que normalmente 
neste tipo de serviço ocorrem, como: afundamento de vala; deformação do revestimento em função do baixo suporte da estrutura do pavimento; ou qualquer outra patologia na reparação executada.

Com a aplicação deste método, o SEMAE obteve um ganho financeiro se compararmos com uma metodologia tradicional utilizando-se agregados primários. $\mathrm{O}$ custo do agregado reciclado, segundo a EMDHAP em 2004 fica em torno de R \$ 5,00 por $\mathrm{m}^{3}$. Nas mineradoras da região, os custos dos agregados primários ficam em torno de $\mathrm{R} \$ 25,00 \mathrm{o} \mathrm{m}^{3}$; a areia $\mathrm{R} \$ 35,00 \mathrm{o} \mathrm{m}^{3}$ e o solo $\mathrm{R} \$ 14,00 \mathrm{o} \mathrm{m}^{3}$.

Portanto, mesmo utilizando-se todo o agregado reciclado no fechamento da vala é possível obter um ganho financeiro e tecnológico em relação aos métodos aplicados por empresas de saneamento, sem prejuízo da qualidade.

Quando comparada com o estabelecido pela Norma Técnica SABESP NST 224. SOPAC, 2006, a metodologia proposta fica menos onerosa em sua execução e mais simplificada, por aplicar materiais de mesma semelhança, o que não ocorre neste método da (SABESP, 2006).

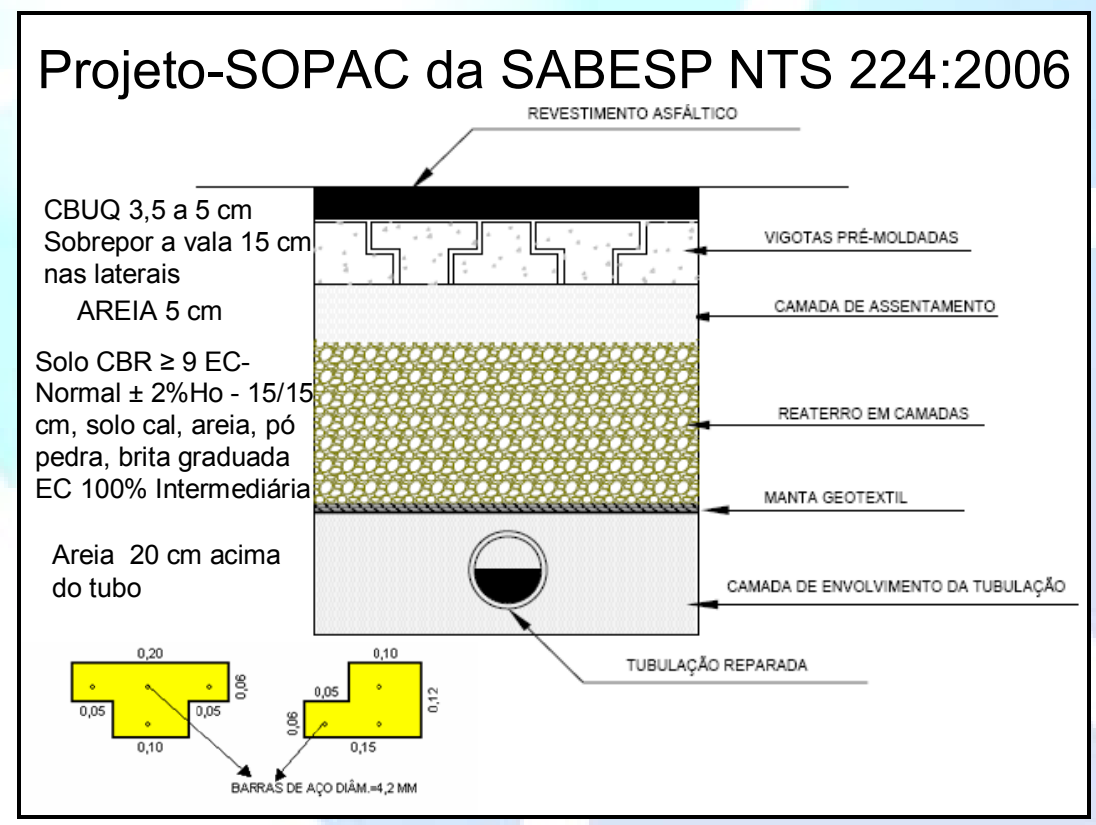

Figura 4. Modelo esquemático do sistema SOPAC da SABESP-SP.

Espera-se com este estudo oferecer à construção civil mais uma opção de utilização destes resíduos, diminuindo-se assim a pressão impactante sobre o meio ambiente, seja na extração de matérias primas, nos aterros de inertes ou no ciclo energético muito discutido na atualidade. 


\section{REFERÊNCIAS}

ABNT - ASSOCIAÇÃO BRASILEIRA DE NORMAS TÉCNICAS. NBR 7181. Solo: análise granulométrica: método de ensaio. Rio de Janeiro, 1984.

: NBR 10004. Resíduos sólidos - classificação. Rio de Janeiro, 2004a.

: NBR 10005. Lixiviação de resíduos - procedimentos. Rio de Janeiro, 2004 b. $2004 \mathrm{c}$.

: NBR 10006. Solubilização de resíduos - procedimentos. Rio de Janeiro,

: NBR 10007. Amostragem de resíduos sólidos - procedimentos. Rio de Janeiro, 2004d.

: NBR 15116. Agregados reciclados de resíduos sólidos da construção civil - Utilização em pavimentação e preparo de concreto sem função estrutural Requisitos - Rio de Janeiro, 2004e.

: NBR 11804. Materiais para sub-base ou base de pavimentos estabilizados granulometricamente - especificação. Rio de Janeiro, 1991.

BRASIL. Ministério do Meio Ambiente. Conselho Nacional do Meio Ambiente CONAMA, Resolução no 307 de 17 de março de 2002. Estabelece diretrizes, critérios e procedimentos para a gestão dos resíduos da construção civil - Disponível na internet:

http://www.mma.gov.br/port/conama/legiano1.cfm?codlegitipo=3\&ano=2002

COELHO, P. E.; CHAVES, A. P. Reciclagem de entulho - Uma opção de negócio potencialmente lucrativa e ambientalmente simpática. Revista Areia \& Brita, Associação Nacional das Entidades de Produtores de Agregados para Construção Civil, n.5, p.31-35. abr./maio/jun. 1998.

DNER - DEPARTAMENTO NACIONAL DE ESTRADAS E RODAGEM. 049:94 Solos determinação do índice Suporte Califórnia utilizando amostras não trabalhadas. ME - Ministério dos Transportes - Rio de Janeiro, 1994a.

. ME 082:94 - Solos - determinação do Limite de plasticidade. ME Ministério dos Transportes - Rio de Janeiro, 1994b.

. ME 122:94 - Solos - determinação do limite de liquidez. ME - Ministério dos Transportes - Rio de Janeiro, 1994c. 
. ME 201:94 - Solo-cimento compressão axial em corpos-de-prova

cilíndricos. ME - Ministério dos Transportes - Rio de Janeiro, 1994d.

IBGE - INSTITUTO BRASILEIRO DE GEOGRAFIA E ESTATÍSTICA.

Metodologia Adotada nas Estimativas Populacionais Municipais. julho de 2002, publicadas no Diário Oficial da União de 30 de agosto de 2002.

ftp://ftp.ibge.gov.br/Estimativas Projecoes Populacao/Estimativas 2002/

FORTES, M. R.; NETO, A. Z.; MENETTI, N. C.; BARBOSA, A. S.; MERIGLI, C. F. A Importância do controle tecnológico e de qualidade na reabilitação de pavimentos após a intervenção de concessionárias em São Paulo. In Anais...36 ${ }^{\mathbf{a}}$ REUNIÃO ANUAL DE PAVIMENTAÇÃO,v. 97. 2005. Curitiba.Anais....Curitiba. 2005.

LIXO MUNICIPAL - Manual de gerenciamento integrado / Coordenação: Maria Luiza D' Almeida, Andre Vilhena - 2a .ed. São Paulo: IPT/CEMPRE, 2000, 179p. Publicação IPT 2622.

LEVY, S.M. Reciclagem do entulho da construção civil, para utilização com agregados para argamassas e concretos. São Paulo, 1977. 147p. Dissertação (Mestrado em Engenharia) - Escola Politécnica, Universidade de São Paulo.

MEHTA, P. K.; MONTEIRO, P. J. M.. Concreto: estrutura, propriedades e materiais. São Paulo: Pini. p.251-254. 1994.

SABESP - SANEAMENTO BÁSICO DO ESTADO DE SÃO PAULO. NORMA TÉCNICA NST 224. SOPAC - Sistema otimizado de pavimento concomitante.

São Paulo, Julho, 2006, 8p. (Procedimento). 